\title{
El baloncesto en la E.G.B.: Técnicas de conducción del balón
}

\author{
G. N. Grigoriev
}

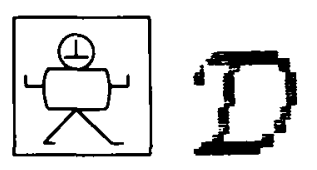

Como se señala en el editorial de este mismo número, donde se ofrece una somera base conceptual para leer este artículo, la literidad más difícil de lograr, el código más difícil de interiorizar, precisamente por ser el menos "externo", es el del dominio del movimiento corporal, que en nuestra cultura está adscrito al deporte y a la educación física. La motivación de los alumnos por la educación física, que a menudo se reduce a unas horas de gimnasia, tiene que entrar por vías a menudo insospechadas. Parece que el baloncesto ha irrumpido con fuerza en el campo de los intereses de los escolares y el tratamiento procedural que se aborda en este articulo permitirá a los profesores sistematizar su práctica como deporte escolar y emplearlo como actividad concreta sobre la que desarrollar una literidad corporal, un dominio consciente $y$ analitico de los movimientos.

\section{EL BALONCESTO EN LAS CLASES DE VI GRADO}

El programa de baloncesto de VI grado (equivalente a $2 .^{\circ}$ de EGB), prevé enseñar a los alumnos a llevar el balón, variando la dirección y la velocidad; pasarlo desde el hombro; y lanzar en movimiento después de haber dado dos pasos. El plan incluye también una serie de juegos en la cancha de minibasket.

\section{CONDUCCION DEL BALON VARIANDO LA DIRECCION Y LA VELOCIDAD}

Conducir el balón en baloncesto es un procedimiento que permite al jugador desplazarse por la cancha a velocidades muy diferentes y hacerlo en

«Basketbol na urókaj v VI klassen Fizicheskaia Kultura v skole, 1987, 1, 11-17. Reproducido con autorización de la VAAP.

(C) Traducción al castellano, CLEE, 1989 (Traducción de José María Bravo).

Comunicación, Lenguaje y Educación, 1989, 2, 77-89 
cualquier dirección. El empleo de este recurso está justificado en juego en los siguientes casos: en primer lugar, para acercarse a la canasta, así como para pasar el balón desde la zona posterior a la anterior y aproximarlo al máximo a la canasta; en segundo lugar, para sacar el balón de una zona en que están concentrados los jugadores del equipo contrario, para romper la defensa y para mantener y dominar el balón durante los últimos segundos del juego (naturalmente, siempre y cuando el equipo vaya ganando).

En clase de baloncesto, el profesor debe avisar a los jugadores de que no hay que abusar de la conducción del balón. Cada uno de los alumnos que practican el juego debe saber que hay que recurrir al regate cuando haga falta y si se está convencido de que todo ello irá en beneficio del equipo.

En el baloncesto se emplea la conducción del balón con bote alto y con bote bajo, variando la velocidad y la dirección.

La conducción del balón con bote alto la utiliza el jugador cuando quiere desplazarse rápidamente por la cancha y en su camino no hay ningún contrario. En tales casos, el torso del jugador debe estar algo inclinado hacia adelante, la cabeza alta, el balón deberá rebotar de la cancha hasta la cintura del jugador. Los dedos de la mano deberán estar separados y ligeramente doblados; el contacto con el balón se realiza con las puntas de los dedos. El movimiento de éstos recuerda más bien un empujón que un golpe. La mano libre de la conducción del balón se desplaza ligeramente hacia un lado y se eleva hasta la altura de la cintura, lo que ayuda a mantener el equilibrio y a cubrir el balón de la acción del contrario. El balón deberá llevarse a una velocidad que permita controlarlo.

La conducción del balón con bote bajo se emplea cuando el contrario trata de llevárselo. La técnica de la conducción por bajo es casi igual que la de la conducción por alto, sólo que la posición del jugador es baja y el balón rebota a poca altura del suelo. A los alumnos hay que explicarles que cuanto más cerca se halle el contrario y más activo sea, más bajo deberá ser el rebote del balón. En la conducción por bajo, el jugador debe mantener el balón lo más cerca que pueda, ayudándose con el brazo libre y con el torso a protegerlo del ataque del contrario.

La conducción del balón variando la velocidad se lleva a cabo a costa de modificar la altura y el ángulo de rebote. El jugador recurre a variar inesperadamente la velocidad de conducción del balón para liberarse del defensa del equipo contrario. La velocidad de conducción del balón depende ante todo de la altura del rebote del mismo y del ángulo con que es dirigido hacia el suelo. Cuanto menor sea el ángulo y mayor el rebote (dentro, naturalmente, de unos límites racionales) mayor será la velocidad de desplazamiento del jugador. En el rebote bajo y próximo a la vertical la conducción se retarda, pudiendo incluso el jugador mantenerse en el mismo sitio.

Durante el proceso de enseñanza y consolidación en las clases de los procedimientos de conducción del balón en el baloncesto es fundamental que el profesor utilice ampliamente el arsenal de los ejercicios que por su contenido se aproximan a las situaciones que se producen durante el juego. Permiten a los alumnos darse cuenta desde las primeras clases de baloncesto del significado y del objetivo de tal o cual procedimiento. Los ejercicios relacionados con la práctica del juego incluidos en las clases de iniciación 
de las formas y de los procedimientos de jugar al baloncesto ayudan a los escolares a dominar rápidamente los procedimientos técnicos, la táctica del ataque y la defensa y a participar antes en los juegos en calidad de jugadores bien preparados, que saben lo que han de hacer.

Ejemplos de ejercicios de juego que ayudan a consolidar y perfeccionar los proce̊dimientos de conducción del balón

1. Conducción del balón con bote alto y con bote bajo. Los ejercicios se realizan colocándose los alumnos en filas, unos frente a otros, primero sin desplazarse y luego avanzando, retrocediendo y moviéndose hacia los lados.

2. Conducción y pase del balón a una señal. Los jugadores se sitúan en columnas, como indica la figura 1 . El jugador 1 de cada una de las columnas lleva el balón hacia la columna opuesta, fijándose en el primer jugador de ella, el cual, utilizando libremente las señales establecidas a priori, marca el ritmo del desplazamiento y en el momento en que adelanta los brazos el jugador 1 debe efectuar el pase. A continuación, este último pasa al extremo de la columna opuesta y el que lleva el balón comienza a conducirlo hacia esa columna.

3. La clase se distribuye en varias columnas. Los cabezas de las mismas inician la conducción del balón hasta el primer lugar señalado empleando un procedimiento (por arriba), luego hasta el segundo lugar (por abajo), efectúan la detención, el giro y pasan el balón al que les sigue en la columna, colocándose a su vez al final de la misma.

FIGURAS 1 y 2
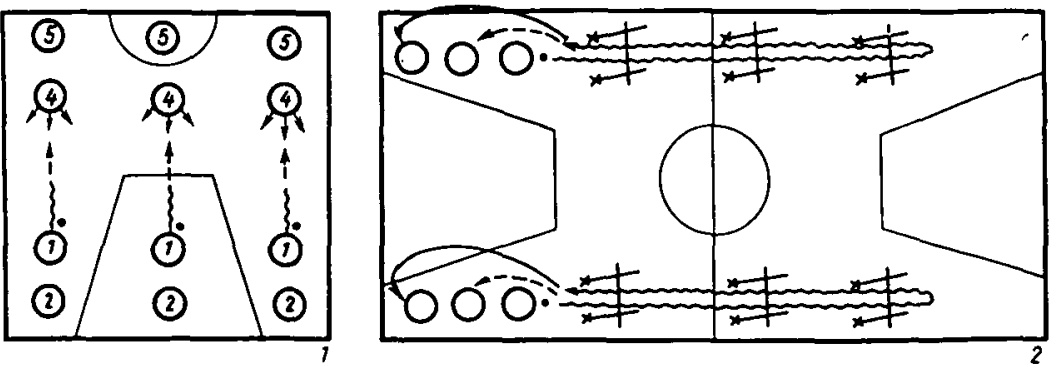

4. Conducción del balón a lo largo de pasillos (se señalan previamente en la cancha). El cabeza de cada columna conduce el balón por dentro del primer pasillo por alto, por dentro del segundo por bajo, luego por alto, etc.

5. Lo mismo que en el ejercicio 4, sólo que la conducción con bote alto pasa a realizarse con bote bajo después de haber esquivado los postes situados frente a cada columna.

6. Dos filas de jugadores se colocan una frente a otra a 3-5 $\mathrm{m}$ de distancia. El jugador situado en el flanco derecho de una de las filas lleva el balón hacia el del flanco derecho de la fila opuesta, al llegar a su altura se lo pasa a las manos, colocándose en su lugar. El jugador que ha recibido el balón lo conduce hacia el segundo jugador de la fila opuesta y se lo pasa también a las manos, colocándose en el lugar que ocupaba éste. Esta con- 
ducción del balón en zigzag continúa hasta que todos los alumnos terminen de participar. A continuación, el ejercicio puede repetirse en sentido opuesto. La conducción se comienza con bote alto, pasándose a realizarla con bote bajo al aproximarse al jugador.

7. Los jugadores se sitúan como se indica en la figura 2. En el trayecto a seguir por cada uno de los jugadores que llevan sucesivamente el balón se colocan columnas provistas de listones transversales a la altura de los hombros de los alumnos. Al acercarse al listón, el jugador que lleva el balón debe pasar a conducirlo por bajo, cruzando el listón por debajo, sin tocarlo. Una vez que ha cruzado todos los listones, da la vuelta y continúa conduciendo el balón en sentido contrario. Cuando se lo ha pasado al siguiente jugador de su columna, se sitúa al final de ésta.

Segunda variante. Después de haber cruzado todos los listones, el jugador puede intentar encestar.

Conducción del balón variando la velocidad. Este procedimiento se utiliza sobre todo para esquivar al contrario y para llegar debajo de la canasta. El cambio de dirección se consigue colocando la mano en distintos puntos de la superficie lateral del balón, enderezando a continuación los brazos en la dirección necesaria. Si inclina el torso hacia el lado del giro. Por lo general, se pasa el balón de una mano a otra. Por ejemplo, para esquivar al contrario por la izquierda el jugador debe colocar durante la conducción la mano derecha en la parte derecha del balón, enviarlo hacia la izquierda enderezando el brazo y al mismo tiempo inclinar el torso hacia la izquier$\mathrm{da}$, apoyando el peso del cuerpo en la pierna izquierda. El jugador debe variar la dirección de la conducción de forma inesperada y, dentro de lo posible, de forma oculta para el contrario, pasando el balón de una mano a otra. Las desviaciones bruscas del torso durante la conducción pueden servir de fintas que oculten la verdadera dirección de la conducción.

Ejemplos de ejercicios de juego, que ayudan a consolidar y perfeccionar la técnica del procedimiento a practicar

1. Los alumnos se colocan como se indica en la fig. 3. El equipo se distribuye en fila de a uno a $3 \mathrm{~m}$ de distancia de 4 banderines, separados $2 \mathrm{~m}$ uno de otro; el balón lo tienen los dos jugadores primeros. El jugador 1 lleva el balón esquivando el primer banderín con el brazo derecho, el segundo con el izquierdo, y así sucesivamente. El jugador 2 puede comenzar la conducción después de que el jugador 1 haya sobrepasado el tercer ban-

FIGURAS 3 y 4

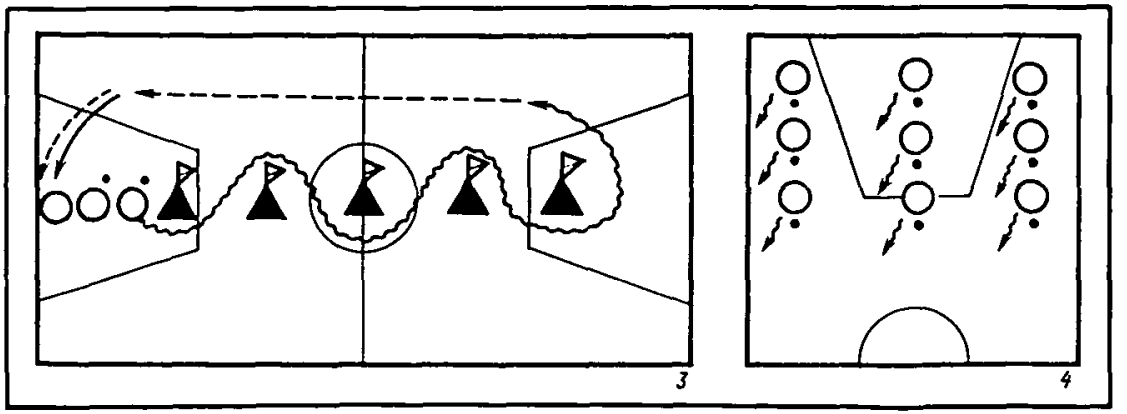


derín. De retorno a la fila, el jugador pasa el balón al alumno siguiente y se coloca al final de la misma.

2. Conducción del balón a una señal. Cada alumno tiene un balón. Los participantes se,encuentran en una de las mitades de la cancha (fig. 4). El profesor está en la otra mitad, en la línea de lanzamiento de las faltas y a una señal (silbato, palmadas) indica la dirección del movimiento: adelante, atrás, a la derecha, a la izquierda o en diagonal. Durante la ejecución del ejercicio, el profesor presta atención a que los alumnos mantengan la cabeza alta y a que ejecuten con precisión su indicaciones.

3. Los participantes están distribuidos en la cancha como se indica en la figura 5. El jugador 1 lleva el balón zigzagueando alrededor de cada jugador, alternado bien con la mano derecha o bien con la izquierda (pero

FIGURAS 5 y 6
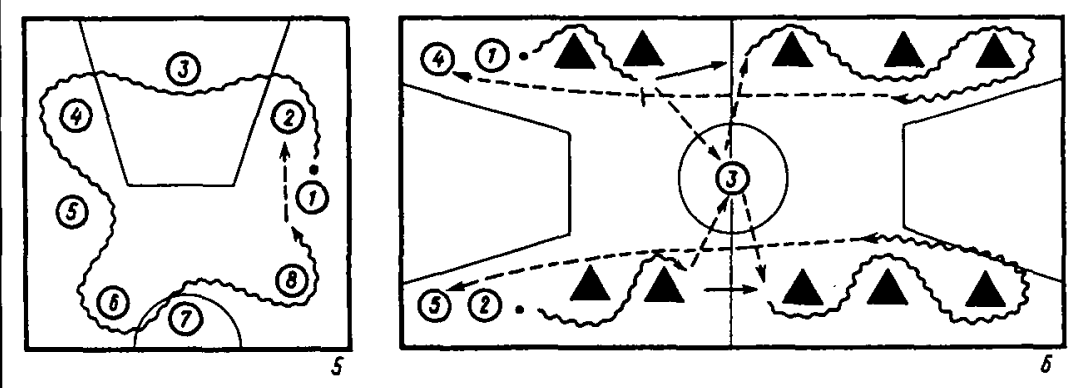

siempre con la que está más lejos del jugador que permanece quieto). Al aproximarse a cada uno de los jugadores, el que está en posesión del balón pasa a conducirlo por bajo. Cuando hay varios balones en la cancha, se puede aumentar el número de jugadores que practican los procedimientos de conducción del balón en cuestión.

4. Los jugadores se colocan en la cancha como se indica en la figura 6, donde los triángulos indican la distribución de los obstáculos. A una orden del profesor, los jugadores 1 y 2 comienzan a esquivar los obstáculos; una vez que han superado dos de ellos, pasan sucesivamenteel balón al jugador 3 , lo reciben de nuevo y continúan llevándolo. Cuando han superado todos los obstáculos, los alumnos pasan el balón a los siguientes: el jugador 2 al 5 , el 1 al 4 , y ellos a su vez se colocan al final de sus filas.

5. Jugar al marro conduciendo el balón. El equipo se coloca en el centro de la cancha, uno de los jugadores lleva el balón (fig. 7). Mientras lo conduce, trata de tocar a uno de los jugadores, a los cuales les está permitido desplazarse a saltos apoyándose en uno o dos pies con las manos en la espalda, dando pasos uno junto a otro, corriendo, incluso en parejas, cogidos de la mano. El jugador tocado pasa a ser quien conduce el balón.

6. Conducción del balón dentro de un cuadrado. Los muchachos se distribuyen en cuatro filas en cuatro ángulos situados en una de las mitades de la cancha (fig. 8). En la otra mitad se distribuyen de igual modo cuatro filas de chicas. El jugador 1 de la primera fila conduce el balón hacia el jugador de la segunda fila, se lo entrega en las manos, volviéndolo a recibir inmediatamente. A continuación, se desplazan ambos hacia la tercera fila, 
llevando el balón el jugador 1. A la mitad del camino entre las filas, el jugador 1 vuelve a pasar el balón al jugador 2 de la segunda fila que le acompaña, el cual a su vez lo conduce hacia el jugador 3 de la tercera fila. El ejercicio continúa hasta que el balón pasa sucesivamente por todas las filas. Una vez realizadas todas las acciones recíprocas, el jugador 1 se coloca al final de la segunda fila, el jugador 2 al final de la tercera, y así sucesivamente. Cuando el ejercicio ha sido asimilado, se pueden introducir balones complementarios.

7. Carrera de relevos llevando el balón. Los jugadores están repartidos en dos filas paralelas situadas en los laterales de la cancha. A una señal, los cabezas de las filas conducen el balón hacia delante en dirección opuesta. Al llegar al lugar marcado, se detienen, lanzan el balón desde el pecho con las dos manos a los jugadores segundos, lo vuelven a recibir y corriendo retroceden con él hacia su fila. A 3-4 m de ella se detienen dando un salto y pasan el balón en la forma indicada al siguiente jugador, colocándose a su vez al final de las respectivas filas. Gana el equipo que termina antes la conducción del balón. El juego se puede complicar colocando ma-

Figuras 7 y 8

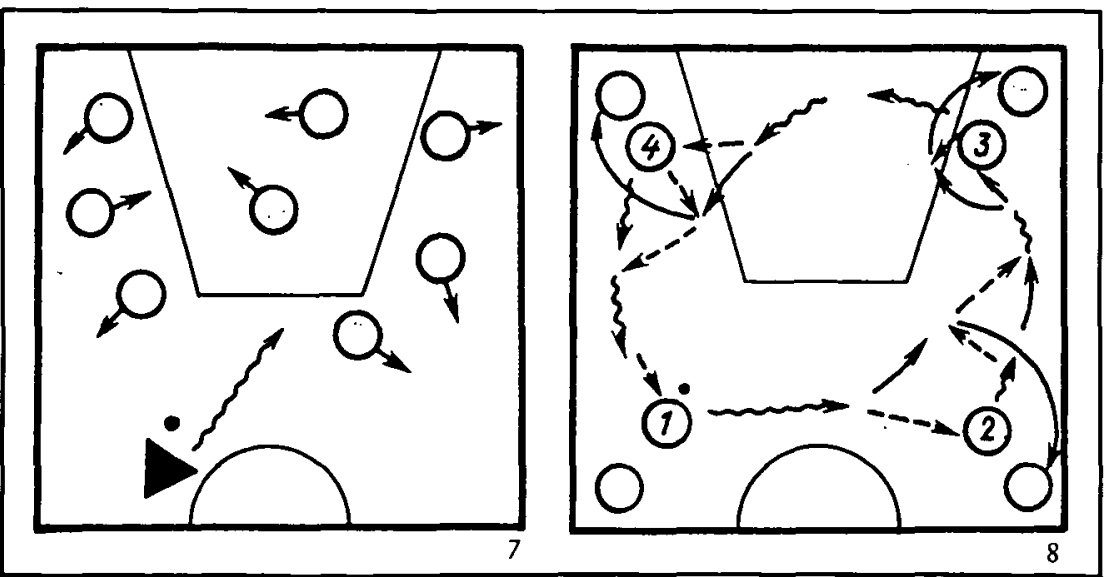

zas (postes) a lo largo de la trayectoria a seguir con el balón; los jugadores han de llevarlo y en el momento de sortear el poste pasar a conducirlo por bajo.

8. Conducción del balón en parejas. Un jugador lleva el balón por toda la cancha, otro intenta quitárselo. En cuanto lo consigue, comienza a llevarlo y el que lo ha perdido pasa a ser defensa y trata de arrebatárselo al contrario. El balón se conduce primero con la mano derecha y después con la izquierda.

9. Cada uno de los participantes tiene un balón. Todos lo conducen simultáneamente, tratando al mismo tiempo de arrebatárselo con la mano libre a cualquiera de las parejas. El jugador al que le ha sido arrebatado el balón debe llevarlo alrededor de la cancha. Sólo después de eso se incorpora nuevamente al juego. El balón se lleva tanto con la mano derecha como con la izquierda. Para hacer más complicado el ejercicio se puede organizar un juego en una mitad de la cancha. 
Pase del balón desde el hombro. El pase del balón con una mano desde el hombro se realiza cuando el jugador lo sostiene con ambas manos, el peso del cuerpo está repartido sobre ambos pies, uno de los cuales, separado del otro a la distancia de un paso, está adelantado (está adelantado el contrario a la mano que lanza el balón).

Conviene comenzar el aprendizaje de este pase empleando el brazo más fuerte. Al efectuarlo con el brazo derecho, se echa el balón hacia la derecha y hacia atrás, a la vez que se gira el torso hacia la derecha y se hace recaer el peso del cuerpo sobre el pie derecho - así es como se lleva a cabo la acción del lanzamiento. El balón lo sostienen los dedos de la mano derecha muy separados, manteniendo el brazo doblado por el codo, con los dedos de la mano colocados detrás del balón. La mano izquierda sujeta el balón por delante y desde abajo.

El pase se lleva a cabo a la vez que se baja la mano izquierda, que sostiene el balón, se gira el torso hacia el lado del pase, trasladando al mismo tiempo el peso del cuerpo al pie adelantado; se da un paso adelante con el pie derecho y antes de apoyarlo en el suelo se envía el balón en la dirección deseada moviendo el brazo y la mano (fig. 9). Este pase se utiliza sobre todo cuando se juega en equipo en los avances rápidos, especialmente en su primera fase, así como para hacer llegar el balón a distancias medias y especialmente lejanas.

Figuras 9 y 10

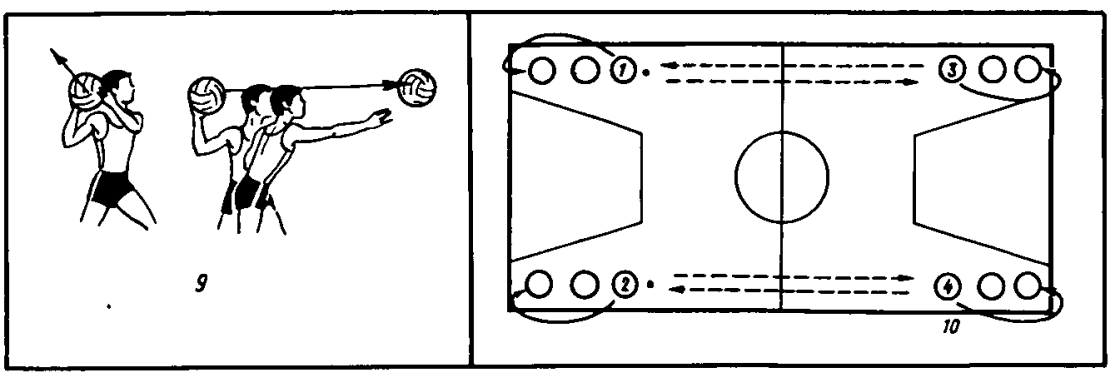

Ejemplos de ejercicios que ayudan a consolidar y perfeccionar la técnica del procedimiento a practicar

1. La clase se divide en dos equipos, que se colocan uno frente a otro en dos filas a lo largo de las líneas laterales de la cancha. Los balones se hallan en poder de los jugadores de una de las filas y cada uno pasa el balón al jugador del equipo contrario situado enfrente de él. El balón se captura igual que en los pases con dos manos desde el pecho. Durante el aprendizaje, el profesor deberá fijar la atención de los alumnos al principio más en el aspecto técnico de la ejecución (la coordinación de la acción de las piernas y los brazos) que en la distancia del pase, la cual se irá aumentando paulatinamente.

2. Lo mismo, pero el jugador deberá salir al encuentro del balón antes de recibirlo, detenerse a la vez que lo captura y pasárselo al contrario con una mano desde el hombro.

3. Lo mismo, pero el jugador que ha recibido el balón habrá de con- 
ducirlo (dar 2-3 rebotes en el suelo), detenerse, pasándoselo a continuación al contrario.

4. Los participantes se distribuyen en dos filas situadas una frente a otra a una distancia de 5-6 m (fig. 10). El balón se halla en poder de los cabezas 1 y 2 de las filas. El jugador lo pasa con una mano desde el hombro al que está en la fila de enfrente y se coloca al final de su fila; el que ha recibido el balón repite la acción.

5. Lo mismo, pero una vez efectuado el pase, el jugador se coloca al final de la fila contraria.

6. Lo mismo, pero el jugador ha de conducir el balón, dar 2-3 rebotes en el suelo, detenerse, pasándoselo seguidamente con una mano desde el hombro al jugador situado enfrente de él. Conviene aumentar paulatinamente la distancia entre las filas hasta $12-15 \mathrm{~m}$.

Cada uno de los ejercicios de juego que acabamos de describir imita en uno u otro grado las situaciones que pueden presentarse durante el juego en el minibasket o en el "gran» basket. Al practicarlos, el profesor de cultura física no debe olvidar los juegos vivos, el contenido de los cuales puede aproximarse al juego deportivo que se trata de aprender. Ofrecemos dos variantes de semejantes juegos.

15 pases. En este juego, los participantes se distribuyen de cuatro en cuatro y se sitúan por parejas a 6-8 pasos de distancia unos de otros. Los números uno se hallan situados frente a los números dos (un equipo) y los tres frente a los cuatro (otro equipo). A una señal, cada pareja deberá realizar lo más rápidamente posible 15 pases con una mano desde el hombro. La pareja de jugadores que haya terminado antes (el jugador levantará la mano) se considerará vencedora. El profesor y sus ayudantes se encargan de efectuar el cómputo de juego, calculando qué pareja ha aventajado a las restantes y qué equipo es el vencedor.

Pase de acuerdo con los números. Los jugadores se dividen en varios equipos de 5-6 personas cada uno. En los equipos, los jugadores se numeran siguiendo un orden. Los números uno reciben el balón. A la orden del profesor « $A$ correr!», los jugadores comienzan a desplazarse por la cancha en distintas direcciones, aunque los miembros de cada equipo deben estar cerca unos de otros. A la orden "iPase!", sin interrumpir el movimiento, se pasan el balón uno a otro con la mano desde el hombro, siguiendo el orden numérico. Duración del juego, 2-3 min.

Los ayudantes del profesor son los encargados de vigilar los pases y la captura del balón por parte de cada equipo. Los errores en los pases y en la captura del balón, así como cada caída de éste al suelo se penalizan con un punto. Resultará vencedor el equipo que haya recibido menos penalizaciones y haya efectuado más pases.

\section{LANZAMIENTO DEL BALON EN MOVIMIENTO DESPUES DE HABER DADO DOS PASOS}

Entre los numerosos lanzamientos que se practican en el baloncesto, el lanzamiento con una mano en movimiento constituye en la etapa inicial del aprendizaje uno de los más importantes, aunque al mismo tiempo es uno de los más difíciles de asimilar. 
El lanzamiento con una mano por alto en movimiento se efectúa desde cerca, directamente a la canasta o desde un lado. Después de haber mostrado a los alumnos su ejecución, el profesor de cultura física trata desde la primera clase que éstos asimilen este procedimiento. Al efectuar el lanzamiento, el jugador salta apoyándose en el pie izquierdo y eleva el balón con ambas manos, sujetándolo por detrás con la derecha, manteniéndolo con los dedos separados. El balón deberá apoyarse en los dedos y no en la palma. El jugador salta con la punta del pie izquierdo y adelanta y eleva la rodilla de la pierna derecha. Mantiene el torso recto y hacia arriba y dirige la mirada hacia el punto hacia donde debe enviar el balón (ángulo superior del rectángulo dibujado en el tablero). Una vez alcanzada la altura máxima del salto, retira del balón la mano izquierda y lo envía suavemente hacia el objetivo con la derecha. Hay que señalar que el salto hacia arriba debe efectuarse apoyándose con fuerza en el pie izquierdo cuando el lanzamiento se realiza con la mano derecha y en el derecho cuando se realiza con la izquierda. El contacto con el suelo se efectúa con ambos pies.

El balón debe salir de las manos sin girar o girando levemente y ser enviado suavemente al tablero. Para conseguirlo, después de avanzar a gran velocidad, el jugador debe detenerse(«mantenerse en el aire») en el punto más alto del salto y centrar toda su atención en que el balón vaya suavemente hacia el objetivo.

Durante el aprendizaje se recomienda realizar todos los tiros con una mano por alto y en movimiento tirando al tablero. Si el jugador ha llegado al tablero de enfrente deberá dar primero un paso a un lado, luego dar otro hacia la canasta y sólo después proceder a lanzar. Analicemos más detalladamente la secuencia del aprendizaje. El alumno debe ser capaz de efectuar los lanzamientos en movimiento tanto con la mano derecha como con la izquierda, ya que éstos han de realizarse con la mano que está «más lejos» de la defensa, cubriendo el balón con el cuerpo: por la derecha, lanzarlo con la mano derecha y por la izquierda del tablero con la izquierda. Hemos de llamar la atención del profesor sobre las dificultades con que tropiezan los alumnos tanto al realizar el lanzamiento en sí como al aprender la técnica de los "pasos». Para superarlas, hay que tener en cuenta lo siguiente: si el balón ha sido capturado después de haber dado el primer paso (obligatoriamente en situación en que se carece de apoyo) con el pie derecho, el lanzamiento deberá realizarse con la mano derecha y al contrario. Cuando las acciones son unilaterales (lanzamiento y salto con la mano y pie derechos) la coordinación se infringe y los lanzamientos carecen de exactitud. Los alumnos deben aprender a conseguir que el primer paso, cuando se apoderan del balón, sea necesariamente largo. Para ello, al avanzar, la planta del pie deberá apoyarse en el talón. El segundo paso con el pie izquierdo deberá ser, por el contrario, corto, con objeto de frenar el movimiento del jugador hacia delante. El paso corto permite que el salto sea más rápido y más potente. La reducción de la inercia del movimiento del jugador hacia delante se consigue frenando el segundo paso y echando el torso hacia atrás. Al mismo tiempo que se da el segundo paso, se atrae el balón hacia el torso. Para aumentar el salto hacia arriba, la pierna se estira hacia arriba doblada por la rodilla. En el punto más elevado del salto se enderezan el brazo y el torso, aproximando al máximo el balón a la canas- 
ta; la rodilla que se elevó al saltar desciende y el balón se empuja con un suave movimiento de la mano y los dedos (fig. 11).

Es muy importante dar el salto hacia arriba y no hacia delante. Cuando el salto es vertical, resulta más fácil encestar, ya que el movimiento del jugador en el aire se vuelve más lento y éste se aproxima suavemente a la canasta. El balón entra en la canasta con mayor precisión después de haber rebotado en el tablero. Una vez realizado el lanzamiento conviene tocar el suelo con las piernas encogidas directamente debajo de la canasta sin perder de vista el movimiento del balón para poder hacerse de nuevo con él en caso de fallo.

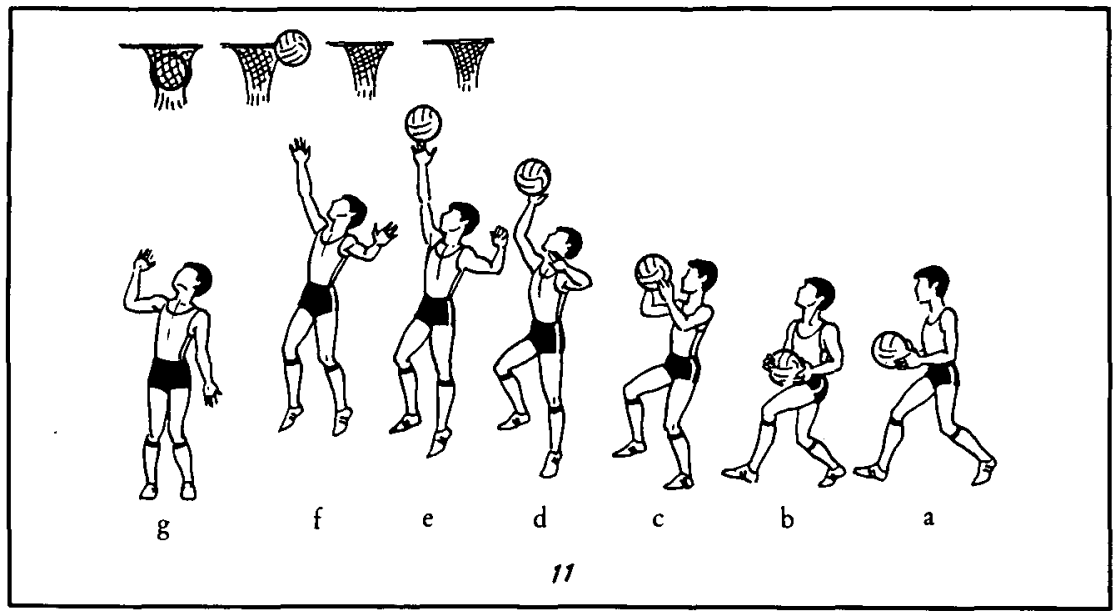

En las clases resulta a veces necesario enseñar a los alumnos paralelamente a lanzar el balón en movimiento por alto a realizarlo con una mano desde abajo. La técnica de ejecución de este lanzamiento es la siguiente: el balón se halla en la palma de la mano vuelta hacia arriba con el brazo recto bajado. El brazo con el balón se mueve hacia delante y hacia arriba y el jugador suelta el balón mediante un activo movimiento de los dedos. En este caso, la técnica de los dos pasos sigue siendo la misma, a excepción del último paso, que no se da verticalmente y hacia arriba, sino hacia arriba a la vez que se realiza un movimiento de avance, aproximando al máximo el balón a la canasta.

Ejemplos de ejercicios que ayudan a consolidar y perfeccionar la técnica del procedimiento a practicar

1. Los jugadores están distribuidos como se indica en la figura 12. El jugador 1 pasa el balón al jugador 2, que se ha situado debajo de la canasta, el cual, apoyándose en el suelo con el pie izquierdo captura el balón durante el salto, toca el suelo con el pie derecho y apoyándose en él da un paso largo (un salto) hacia delante, toca el suelo con el pie iźquierdo y se apoya en él para dar un salto hacia arriba y no hacia delante y en el punto más alto de su ascensión procede a lanzar con una mano. Seguidamente, el jugador 2 recoge el balón y pasa a ocupar el puesto del jugador 1 para pasárselo al jugador 3 , que se sitúa debajo de la canasta. 

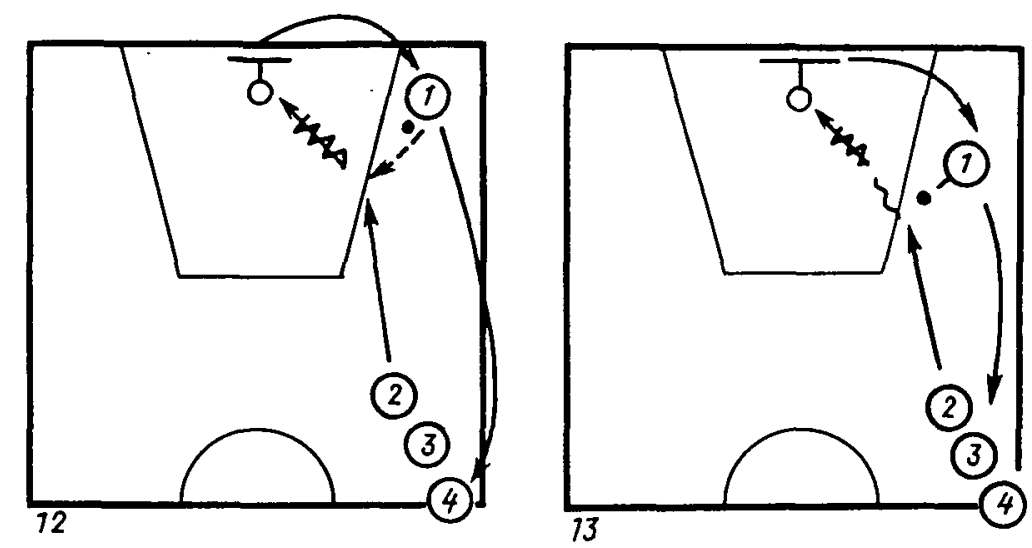

Este ejercicio es bastante complicado y por eso es recomendable realizarlo dividiéndolo en partes. La dificultad estriba, en primer lugar, en conseguir un trabajo correcto de las piernas, sobre todo en el momento de capturar el balón. Para conseguir una mejor asimilación se pueden dibujar en la cancha unas marcas especiales para lograr la colocación adecuada de los pies y la secuencia correcta de su trabajo, así como la dirección a seguir por el jugador que lleva el balón para colocarse debajo de la canasta. La ejecución exitosa de este ejercicio dependerá en alto grado de que el pase se realice en el debido momento y de que sea exacto (suave y con una trayectoria reducida). Por eso, al principio, conviene que quien realice el pase sea el propio profesor o el alumno mejor preparado, que domine bien la técnica del mismo.

Una vez hechas las señales convencionales, se pueden practicar con los alumnos una serie de ejercicios preliminares de orientación.

2. Para perfeccionar el ritmo de los pasos. El jugador que lleva el balón salta impulsándose con el pie izquierdo y toca el suelo con el derecho; seguidamente da un salto hacia delante, toca el suelo con el pie izquierdo y apoyándose en él lanza el balón a la canasta.

3. Para practicar la captura del balón estando apoyado en el pie derecho. El jugador de pie con el balón, manteniendo adelantado el pie izquierdo, lo suelta delante de sí, golpeándolo en el suelo y saltando con el pie derecho lo captura, toca el suelo con el mismo pie, vuelve a saltar, toca el suelo con el izquierdo, salta hacia arriba apoyándose en él y al alcanzar el punto más alto lanza el balón a la canasta.

4. Para practicar la captura del balón sin apoyarse se puede colocar en la trayectoria del movimiento a realizar por el lanzador un pequeño obstáculo, preferentemente una alfombrilla de perolón enroscada $(30 \times 80 \mathrm{~cm})$ en forma de cilindro de $30 \mathrm{~cm}$ de altura, que los alumnos deberán saltar y durante el salto capturar el balón enviado por el compañero.

5. Para practicar el último paso (salto hacia arriba) se puede colocar bajo la canasta el mismo obstáculo cilíndrico de porolón, delante del cual deberá tocar el suelo el alumno que ejecuta el ejercicio. Eso obliga, al dar el último paso, a saltar hacia arriba en lugar de hacia delante. 
El procedimiento metodológico descrito debe utilizarse una vez que losalumnos hayan asimilado en su totalidad el elemento técnico en cuestión. En función de la velocidad de ejecución del procedimiento, el obstáculo cilíndrico de porolón puede colocarse más o menos lejos de la proyección de la canasta.

6. Los jugadores se distribuyen según el esquema de la figura 13. El jugador 1 sujeta el balón con la palma de la mano abierta. El jugador 2 se acerca corriendo a él y apoyándose en el pie izquierdo quita el balón al jugador 1 estando en el aire, da dos pasos y efectúa el lanzamiento con una mano por alto.

Todos los ejercicios de lanzamiento en movimiento deben ejecutarse primero desde la parte derecha del tablero con la mano derecha y después desde la izquierda con la mano izquierda. En estos casos, hay que recordar que al efectuar el lanzamiento desde la izquierda del tablero, el orden de ejecución de los «dos pasos» será el inverso: capturar el balón apoyándose en el pie izquierdo, tocar el suelo con el mismo pie, dar el paso y volver a tocar el suelo con el pie derecho, saltar hacia arriba con ese mismo pie y efectuar el lanzamiento con la mano izquierda.

La práctica ha demostrado que los lanzamientos de por sí ofrecen un interés bastante estable para los alumnos. Para mantenerlo a lo largo de toda la clase de baloncesto hay que incluir en ella ejercicios de lanzamiento en forma de competiciones.

1. Ante cada canasta (se pueden utilizar tableros complementarios si se dispone de ellos), se forman filas (equipos) de alumnos. Los jugadores de cada fila efectúan uno tras otro un lanzamiento. Vencerá el equipo que haya conseguido mayor número de encestes. Los lanzamientos pueden efectuarse desde el sitio y en movimiento.

2. Lo mismo, pero los lanzamientos habrán de efectuarse en un tiempo determinado. Resultará vencedor el equipo que haya conseguido mayor número de encestes en el tiempo establecido. El número de balones para cada fila es el mismo.

3. Los jugadores se colocan en filas situadas delante de cada tablero. Los primeros jugadores de las filas lanzan el balón a la canasta, pudiéndolo recoger después de que haya rebotado del tablero o de que haya pasado ante la canasta sin entrar y repetir el lanzamiento. Seguidamente, realizan el ejercicio los restantes miembros de la fila. Vencerá el equipo que haya conseguido más puntos. El enceste al primer intento valdrá 2 puntos y al segundo 1 . El jugador que no haya conseguido hacerse con el balón después del primer rebote contra el suelo perderá el derecho a efectuar un segundo lanzamiento.

4. Lo mismo, pero después del primer lanzamiento, el jugador debe capturar el balón en el aire; de lo contrario, pierde el derecho a un segundo lanzamiento. En este caso, cada enceste vale 2 puntos.

Todos los ejercicios de juego con lanzamiento han de realizarse desde diferentes lados del tablero (por la izquierda, por la derecha, desde el centro, desde diferentes ángulos), así como desde distintas distancias, tanto con la mano derecha como con la izquierda.

Posible distribución por clases del contenido de la parte correspondien- 
te al "Baloncesto" en el VI grado. El material didáctico se distribuye a lo largo de las ocho clases previstas en el plan de estudios.

Clase 1. Conducción del balón por alto y por bajo. Pase del balón con una mano desde el hombro sin desplazarse.

Clase 2. Conducción del balón variando la velocidad. Pase del balón con una mano por alto en movimiento en filas situadas al encuentro una de otra.

Clase 3. Conducción del balón variando la dirección. Lanzamiento del balón con una mano por alto en movimiento. Juego al minibasket.

Clase 4. Conducción del balón variando la dirección y la velocidad. Lanzamiento del balón con una mano por alto en movimiento. Juego al minibasket.

Clase S. Pase del balón con una mano desde el hombro en movimiento. Lanzamiento con una mano por alto en movimiento. Juego al minibasket.

Clase 6. Pase del balón con una mano desde el hombro después de llevarlo. Lanzamiento del balón con una mano por alto en movimiento. Juego al minibasket.

Clase 7. Lanzamiento del balón con una mano por alto y por bajo en movimiento después de llevarlo. Juego al minibasket.

Clase 8. Ejercicios de control de la técnica de ejecución de los procedimientos practicados de juego al baloncesto: conducción del balón variando la velocidad y la dirección (fijando el tiempo); pase del balón con una mano desde el hombro (controlando la dirección y la exactitud del pase); lanzamiento del balón con una mano por alto en movimiento (se valorará la técnica de la ejecución y el número de encestes). Juego al minibasket.

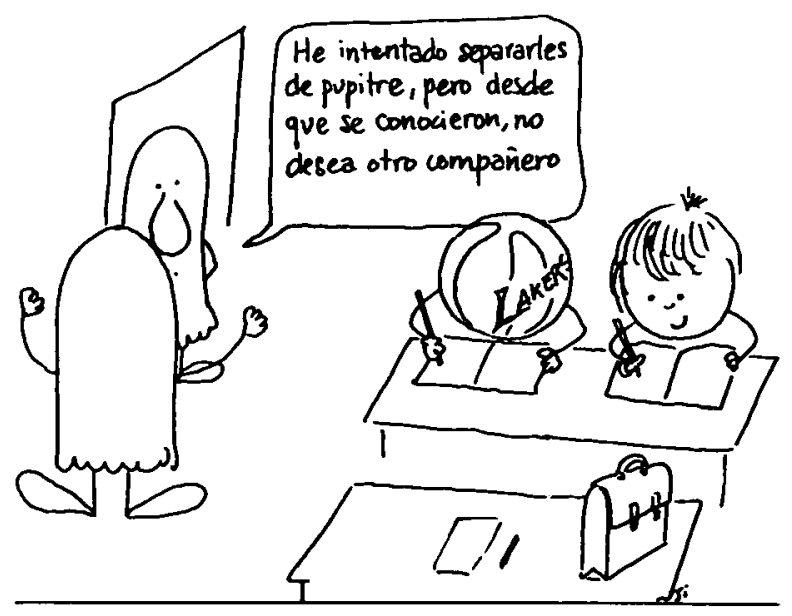

